\title{
A New Era of Liver Transplantation - Radioembolization, a Novel Therapy for Hepatocellular Carcinoma
}

Hima Bindu A* $^{*}$

Andhra Vidyalaya P.G College, Osmania University, Hyderabad, India

\begin{abstract}
Liver failure is one of the major causes of death worldwide and a growing health problem. Now-a-days liver transplantation has been an accepted method to treat many liver disorders. Orthotopic liver transplantation (OLT) is a life-saving procedure for end-stage liver failure. Liver transplantation has some complications involved such as immunosuppression, graft rejection and various side effects. Hepatocellular carcinoma (HCC) is one of the most frequently occurring malignancies and orthotopic liver transplantation is not recommended for patients with Hepatocellular carcinoma. Today, transplantation is entering a new era characterized by a growing interest in novel methods for the treatment of disease that do not necessarily require transferring solid organs between patients. Radioembolization (RE) with radiolabeled microspheres, generally Yttrium-90 microspheres is one such novel method. In this review, a brief emphasis on radioembolization has been described.
\end{abstract}

Keywords: Liver failure; Liver metastasis; Liver transplantation; Hepatic transplantation; Orthotopic liver transplantation; Living donor liver transplantation; Immunosuppression; Graft rejection; Radioembolization

Abbreviations: LT: Liver transplantation; OLT: Orthotopic liver transplantation; HCC: Hepatocellular Carcinoma; ALF: Acute liver failure; DILI: Drug-induced liver injury; CRLMs: Colorectal liver metastasis; NLMs: Neuroendocrine liver metastases; OPN: Osteopontin; BA: Biliary atresia; CRP: C - reactive protein; SGOT: Serum glutamic oxaloacetic transaminases; SGPT: Serum glutamic pyruvic transaminase; PHO-S: Synthetic Phosphoethalomanine; LDLT: Living donor liver transplantation; HTLV: Human T-cell Lymphoma Virus; NODAT: New onset diabetes mellitus after transplantation; MPS: Mononuclear phagocyte system; MSCs: Mesenchymal Stem Cells; MSNs: Mesoporous silica nanoparticles; RE: Radioembolization; SIRT: Selective internal radiation therapy; TACE: Trans Arterial chemoembolization

\section{Introduction}

The liver is the largest organ in the human body, the second to brain in organ complexity. Liver is the main metabolizing organ in the body [1] and displays main digestive function for the metabolism of substances such as carbohydrates, fats, proteins, vitamins, and hormones. In addition to digestion, it functions in the biodegradation of xenobiotics, production of various plasma proteins and production of red blood cells during embryonic development [2]. It is mainly responsible for the immunologic equilibrium hence any disturbance in its function will compromise the immune state [3].

Liver failure is one of the major causes of death worldwide and a growing health problem. Liver metastasis remains the leading cause of death. The liver remains the most common site of metastases in colorectal cancer, with $60 \%$ of patients with metastatic disease having liver involvement [4]. Liver transplantation or Hepatic transplantation is the replacement of a diseased liver with a healthy liver allograft. Generally the native liver is removed and replaced by the donor organ in the same anatomic location as the original liver, the technique called orthotopic transplantation. Orthotopic liver transplantation (OLT) is a life-saving procedure for end-stage liver failure [5]. Now-a-days liver transplantation has been an accepted method to treat many liver disorders. Hepatocellular carcinoma (HCC) is one of the most common malignant tumors worldwide [6]. Liver Transplantation is the most effective treatment for patients with Hepatocellular Carcinoma as it removes the tumor and surrounding cirrhotic tissue which is the main risk factor for the development of new tumors [7].

Adult-to-adult living donor liver transplantation is generally carried out [8]. The transplantation of liver mainly depends on two factors first, the employment of a satisfactory operative procedure and second, the use of suitable measures to prevent the immunologic rejection of the graft [9]. Throughout the history of liver transplantation many improvements have been made in the field of surgical technique [10].

Some of the leading reasons for liver transplantation are as follows-

- Autoimmune hepatitis, chronic viral hepatitis, alcoholic liver disease, metabolic diseases, cholestatic liver disorders, severe acute liver failure due to viral hepatitis, drug-induced hepatitis etc are the main causes of Liver transplantation [11].

- Hepatitis-B patients with decompensated cirrhosis, Hepatocellular Carcinoma (HCC) and acute liver failure (ALF) [12].

- Drug-induced liver injury (DILI) is the leading cause of ALF [13].

- Hepatitis-C Virus is the common cause of cirrhosis and liver

*Corresponding author: Hima Bindu A, P.G Department of Biotechnology, Andhra Vidyalaya P.G College, Affiliated to Osmania University, Hyderabad, India; E- Mail: bindu2889@gmail.com

Received November 02, 2011; Accepted December 24, 2011; Published December 27, 2011

Citation: Hima Bindu A (2011) A New Era of Liver Transplantation Radioembolization, a Novel Therapy for Hepatocellular Carcinoma. J Cancer Sci Ther S17. doi:10.4172/1948-5956.S17-012

Copyright: (C) 2011 Hima Bindu A. This is an open-access article distributed under the terms of the Creative Commons Attribution License, which permits unrestricted use, distribution, and reproduction in any medium, provided the original author and source are credited. 
cancer and is the most common reason for liver transplantation [14].

- Hepatitis B or C viruses cause liver cancer [15].

- Hepatocellular carcinoma (HCC), the most common liver tumor is a leading cause of mortality [7].

- HIV infection [16].

- Liver Fibrosis [17].

- Liver Inflammation [18] - The triggers of chronic inflammation increase cancer risk or progression caused by hepatitis viruses for liver carcinoma [19].

- Tumors of the liver such as hepatocellular carcinoma (HCC), colorectal liver metastasis (CRLMs) and liver metastases from neuroendocrine tumors (NLMs) [20].

- Osteopontin (OPN), a secreted phosphoprotein plays a critical role in metastasis of liver cancer [21]

- In children, biliary atresia is the most common cause of liver failure and the need for a liver transplant. Biliary atresia (BA) is a disease in newborns in which the bile ducts are absent, damaged, or blocked. As a result, toxic bile builds up in the liver, resulting in cirrhosis. BA is the most common indication for pediatric liver transplantation [22].

- The excessive use of paracetamol containing pharmaceuticals has a negative influence on the metabolic functions of the liver [23].

- Chronic exposure to Cadmium (Cd) is also one of the important factors for the liver damage [24].

Various biomarkers on cancer cells of liver include EDDR1 [25], and CD133, a transmembrane glycoprotein as a tumor stem cell marker for liver tumors [26] and increased levels of C-Reactive Protein (CRP) [27]. The diagnosis of liver diseases can be supported by eosinophilia, elevated liver enzymes and hypergamaglubinemia (a type of immunoproliferative disorder, medical condition with elevated levels of gamma globulin) [28]. Serum glutamic oxaloacetic transaminases (SGOT), serum glutamic pyruvic transaminase (SGPT) are the most useful measures for hepatocellular damage [29,30]. Liverbased in vitro modeling provides a good reflection of the hepatic in vivo situation [31]. In mice models, it was found that PHO-S (Synthetic Phosphoethalomanine) inhibits metastases to liver, increases survival rate and decreases tumor volume [32]. Erythropoietin has a protective effect on tissue injury of the liver [33].

\section{Immunosuppression and Graft Rejection}

Before split or living donor liver transplantation (LDLT), liver grafts were generally checked for graft size mismatching [34]. Recent advances in immunosuppressive drug regimens have changed the outcome of liver transplantation; however graft rejection remains the major problem [35]. Liver rejection may happen any time after the transplant. After a liver transplantation, there are three types of graft rejection that may occur. They include hyperacute rejection, acute rejection and chronic rejection. Hyperacute rejection is caused by preformed anti-donor antibodies and it occurs within minutes to hours after transplantation. Acute rejection is mediated by $\mathrm{T}$ cells and involves direct cytotoxicity and cytokine mediated pathways. Acute rejection is the most common and the primary target of immunosuppressive agents and occurs within days or weeks of the transplant. Chronic rejection is the presence of any sign and symptom of rejection after 1 year. Like most other allografts, a liver transplant will be rejected by the recipient unless immunosuppressive drugs are used. Rejection occurs when a person's immune system recognizes the transplanted liver as "foreign" and tries to destroy it. Rejection does not always cause noticeable symptoms. Elevated liver enzyme levels in the blood may be the first sign that rejection is occurring.

Immunosuppressive medications are used to decrease the activity of the recipient's immune response to prevent and treat rejection. Transplant recipients must take immunosuppressive medications for the rest of their life to prevent rejection. Most liver transplant recipients receive corticosteroids. Calcineurin inhibitors are the most commonly used immunosuppressive drugs in liver transplantation [36]. The introduction of cyclosporine as an immunosuppressive agent improved the results and allowed liver transplantation to become the choice of treatment for many patients with end-stage liver disease [37].

Immunosuppressive medications can have significant side effects. By suppressing the immune system, the medications can make patients more susceptible to infections. Unfortunately, these medications cause a variety of side effects such as diabetes, hypertension and nephrotoxicity which in turn result in significant morbidity and reduced quality of life [38]. Long-term use of immunosuppressive medications can also increase a person's risk of developing cancers of the skin and other sites.

\section{Implications of Liver Transplantation}

There are many possible complications of a liver transplant surgery.

- Massive blood loss and associated blood transfusion remains one of the most important factors of perioperative morbidity and mortality in orthotopic liver transplantations.

- A massive transfusion of blood and coagulation factors is required to compensate rapidly developing acute anemia [39].

- The donors must be checked for the presence of Human T-cell Lymphoma Virus (HTLV) before transplantation [40].

- Infections can be one of the causes of morbidity and mortality in postoperative liver transplantation (LT), and immunosuppression therapy can increase a patient's risk of infection [41].

- New onset diabetes mellitus after transplantation (NODAT) is a serious and common complication following solid organ transplantation [42].

- NODAT has an adverse impact on patient and graft outcomes [42].

- Graft rejection.

- Liver diseases can lead to Breast cancer [43], chronic urticaria, and carcinoid syndrome with liver metastases [44].

- Atrazine, a chorotriazine herbicide has been known to cause liver damage in humans [45].

- Sometimes Deaths of living liver donors can occur [46].

- Massive pulmonary hemorrhage and other serious 
cardiopulmonary diseases in patients with fulminant hepatitis result not only in graft failure but also mortality after Liver Transplantation [47].

There are various novel therapies for the treatment of Liver disorders such as Nanotherapy, Stem cell therapy and Radioembolization. In this review few drawbacks of Nanotherapy and Stem Cell therapy are described and more emphasis is given on Radioembolization.

Nanotherapy- Now-a-days the bioavailability of the nanozyme for liver is substantially increased [48]. Larger nanoparticles might be too big to pass through small capillaries for drug delivery. In the case of particle size, the clearance rate of very small nanoparticles might be high, and most of these nanoparticles might end up in the liver making the use of targeted nanoparticles impractical and ineffective. Thus selecting the right materials and particle size is an important aspect in targeted nanoparticles for cancer therapy [49]. The body attempts to remove the offending material from circulation through various routes such as the various cells and components of the mononuclear phagocyte system (MPS) found in the liver [50]. The in vivo biodistribution and urinary excretion of spherical PEGylated mesoporous silica nanoparticles (MSNs) showed liver distribution [51].

Stem Cell Therapy- Various in vitro and in vivo studies have evaluated the safety, feasibility and efficacy of transplanting Mesenchymal Stem Cells (MSCs) for clinical trials. Cellular transplantation into animal models has demonstrated that MSC can engraft into organs like liver, bone, lung and kidney after infusion [52]. Embryonic stem cells have the Ethical issues and concerns like Embryo destruction and fetal injury to extract the embryonic stem cells as a source to generate new cells in the laboratory [53]. Ethical issues and concerns make the reduced use of embryonic stem cells as a source to cure liver diseases when compared to adult stem cells.

\section{Radioembolization, as a Novel Method}

Primary liver cancer is the fifth most common cancer worldwide and the third most common cause of cancer mortality. Hepatocellular carcinoma (HCC) is one of the most frequently occurring malignancies [54]. Orthotopic liver transplantation is not recommended for patients with Hepatocellular carcinoma [55]. The use of external beam irradiation has historically played a limited role in the treatment of HCC due to the radiosensitive nature of normal hepatic tissue [56,57]. Early detection of hepatocellular carcinoma (HCC) through surveillance programmes allows potentially curative therapies such as resection, liver transplantation [58]. The treatment of liver malignancies has evolved over recent decades while the patients with liver tumors were considered incurable previously. Long term survival and even cure of liver tumors has become possible with the advent of safer surgery and adjuncts such as radiospheres [20].

Today, transplantation is entering a new era characterized by a growing interest in novel methods for the treatment of disease that do not necessarily require transferring solid organs between patients [59]. Radioembolization (RE) with radiolabeled microspheres, generally Yttrium-90 microspheres is one such modality. The hepatic artery administration of beta-emitting particulate radiopharmaceuticals is an attractive approach to deliver therapeutic irradiation to the liver and to tumors within the liver [60].

External beam radiotherapy has limited application for the treatment of Hepatocellular Carcinoma because of the risk of radiation- induced liver disease. Transarterial radioembolization with $90 \mathrm{Y}$ glass microspheres allows selective lobar, segmental or subsegmental treatment [61]. Selective internal radiation therapy (SIRT), otherwise known as radioembolization is now becoming a common procedure performed for those patients with primary hepatic neoplasia such as hepatocellular carcinoma and liver dominant metastatic diseases such as colorectal liver metastasis (CRLMs) and liver metastases from neuroendocrine tumors (NLMs) [62,63].

Radioembolization (RE) is defined as the intra-arterial delivery of micron-sized microspheres embedded with a radioisotope that become permanently embedded preferentially in a tumor than to normal tissues [64] and delivers high dose of radiation to the liver tumors. The principle of radioembolization involves the intended deposition of radioactivity into microvascular bed of a biologically active tumor using a carrier-based delivery mechanism [65]. It is usually offered to patients with advanced liver cancers who donot respond for local ablation, surgical resection, liver transplantation (LT) or have failed other previous treatment as Trans Arterial chemoembolization (TACE) or chemotherapy [66]. Radioembolization is used to treat tumors that began in the liver or have spread, or metastasized to the liver from another part of the body.

RE with Ytrium-90 microspheres is a technique that has been developed to target multiple sites of disease within the liver as a form of brachytherapy. Unlike most organs, the liver has a dual blood supply: the hepatic artery and the portal vein [67]. The tumor derives the majority of its blood supply from the hepatic artery and this characteristic ensures that the injected microspheres lodge in the tumor microvasculature, whereas the normal liver tissue receives its blood supply from the portal venous system [68]. SIRT with Y-90 Spheres is useful in reducing or stabilizing multiple liver metastases from a variety of tumors [69,70] and to treat patients with Hepatocellular Carcinoma [71].

There are few drawbacks and limitations of radioembolization technique-

- Chance of infection or allergic reaction at the site of injection of the catheter.

- Risk of microspheres being lodged in the wrong place.

- Allergic reactions to contrast material.

- Not recommended for patients with severe liver or kidney dysfunction, abnormal blood clotting or blockage of bile ducts.

Adequate patient selection and treatment planning is an important criterion for a safe and cost-effective administration of selective internal radiotherapy (SIRT) of malignant liver disease using 90Y-labelled microspheres [72]. Computer simulation of $90 \mathrm{Y}$-microsphere transport in the hepatic arteries is a powerful tool that can determine appropriate conditions for the preferential directing/targeting of 90Y-microspheres to the tumor sites [73].

\section{Conclusion}

Recent advances in diagnosis and treatment of liver disorders have improved the mode of liver transplantation. Radioembolization is a novel method of treatment for liver malignancies. It is a combination of radiation therapy and embolization that helps in effective transfer of microspheres to the site of tumor. Microspheres filled with radioactive Y-90 isotope become lodged at the tumor site where they deliver a high 
Citation: Hima Bindu A (2011) A New Era of Liver Transplantation - Radioembolization, a Novel Therapy for Hepatocellular Carcinoma. J Cancer Sci Ther S17. doi:10.4172/1948-5956.S17-012

Page 4 of 5

dose of radiation. It does not cure the disease but helps to slow down the growth of the disease. Hence, Radioembolization has become the main option for patients where surgery or even liver transplantation is not desirable. Now-a-days it is the most common method for the treatment of Hepatocellular Carcinoma.

\section{Acknowledgements}

I would like to thank my friends for their support in writing this article.

\section{References}

1. Grundmann $O$ (2010) The Gut Microbiome and Pre-systemic Metabolism: Current State and Evolving Research. J Drug Metabol Toxicol 1: 104.

2. Ying J, Quanjun W, Jinglan W, Songfeng W, Gang C, et al. (2008) Profiling of Phosphorylated Proteins in Human Fetal Liver. J Proteomics Bioinform 1: 437-457.

3. Castellanos MI, Seijas OR, González D, Ronquillo M, del Rosario Abreu M, et al. (2011) Immune Alterations in Liver Cirrhosis: Its Relationship with Etiology, Child Pugh Stage and Malnutrition. J Nutrition Disorder Ther 1: 101.

4. Meyer JE, Cohen SJ (2011) Beyond First-Line Therapy: Combining Chemotherapy and Radioembolization for Hepatic Colorectal Metastases. J Nucl Med Radiat Ther 2:103.

5. Beath S, Pearmain G, Kelly D, McMaster P, Mayer A et al. (1993) Liver transplantation in babies and children with extrahepatic biliary atresia. J Pediatr Surg 28: 1044-1047.

6. Kumar R, Saraswat MK, Sharma BC, Sakhuja P, Sarin SK (2008) Characteristics of hepatocellular carcinoma in India: a retrospective analysis of 191 cases. QJM 101: 479-485.

7. Sapisochin G, Charco R (2011) Salvage Liver Transplantation for HCC: An Old Story without Consensus? J Transplant Technol Res 1:106e.

8. Marco A (2000) Right Lobe Living Donor Liver Transplantation: A Review. Liver Transpl 6: 3-20.

9. Starzl Te, Marchioro TI, Vonkaulla Kn, Hermann G, Brittain Rs, et al. (1963) Homotransplantation of the Liver In Humans. Surg Gynecol Obstet 117: 659676

10. Llado L, Figueras J (2004) Techniques of orthotopic liver transplantation. HPB (Oxford) 6: 69-75.

11. Quiroga S, Sebastià MC, Margarit C, Castells L, Boyé R et al. (2001) Complications of Orthotopic Liver Transplantation: Spectrum of Findings with Helical CT. RadioGraphics 21: 1085-1102.

12. Mukherjee S (2009) Antiviral Therapy for Hepatitis B in Pre and Post-liver Transplant Patients. J Antivir Antiretrovir 1: 017-027.

13. Yang X, Li Z, Su Z, Davis K, Chen T, et al. (2011) Urinary Micrornas as Noninvasive Biomarkers for Acetaminophen-Induced Liver Injury. J Postgenom Drug Biomark Develop 1:101.

14. Ramsey SE, Engler PA, Steinw MD, Brown RA, Cioe P et al. (2011) Effect of CBT on Depressive Symptoms in Methadone Maintenance Patients Undergoing Treatment for Hepatitis C. J Addict Res Ther 2:109.

15. Sudhakar A (2009) History of Cancer, Ancient and Modern Treatment Methods. J Cancer Sci Ther 1: i-iv.

16. Patel AK, Patel KK, Ranjan R, Patel AR, Patel JK (2010) Seronegative HIV-1 Infection, a Difficult Clinical Entity; a Case Report. J AIDS Clinic Res 1:106.

17. Mira JA, López-Cortés LF, Vispo E, Tural C, Laguno M, et al. (2010) Concomitan Nevirapine Therapy is Associated with Higher Efficacy of Pegylated Interferon Plus Ribavirin among HIV/Hepatitis C Virus-Coinfected Patients. J AIDS Clinic Res 1:112.

18. Mata RC, Mira JA, Rivero A, López-Cortés LF, Torres-Tortosa M, et al. (2010) Nevirapine-based Antiretroviral Therapy is Associated with Lower Plasma Hepatitis C Virus Viral Load among HIV/Hepatitis C Virus-Coinfected Patients. J AIDS Clinic Res 1:110.

19. Singh RK, Sudhakar A, Lokeshwar BL (2011) From Normal Cells to Malignancy:
Distinct Role of Pro-inflammatory Factors and Cellular Redox Mechanisms. J Cancer Sci Ther 3: 070-075.

20. Lowe K, Jeyarajah DR (2011) Integration of Surgery and Radioembolization in Treatment of Hepatic Tumors. J Nucl Med Radiat Ther 2:105

21. Mi Z, Guo H, Markovic J, Kuo PC (2009) Characterization of Osteopontin Binding Kinetics In MDA-MB231 Breast and SK-Hep-1 Liver Cancer Cells. J Cancer Sci Ther 1: 047-051.

22. Fouquet V, Alves A, Branchereau S, Grabar S, Debray D et al. (2005) Longterm outcome of pediatric liver transplantation for biliary atresia: A 10-year follow-up in a single center. Liver Transpl 11: 152-160.

23. Polaniak R, Bułdak RJ, Jacheć W, Helewski K, Wojnicz R, et al. (2011) Long-term Exposure to Acetaminophen is a Crucial for Activity of Selected Antioxidative Enzymes and Level of Lipid Peroxidation Process in Rat Liver. J Bioequiv Availab 3: 182-186.

24. Mahran AA, Husam Eldien HO, Abd El-Mawla AMA, Attia AM (2011) Protective Effect of Zinc (Zn) on the Histology and Histochemistry of Liver and Kidney of Albino Rat Treated with Cadmium. J Cytol Histol 2:123.

25. Sinnathamby G, Zerfass J, Hafner J, Block P, Nickens Z, et al. (2011) EDDR1 is a Potential Immunotherapeutic Antigen in Ovarian, Breast, and Prostate Cancer. J Clin Cell Immunol 2:106.

26. Shrihari TG (2011) Cancer Stem Cells - Therapeutic Boon! J Cancer Sci Ther 3: $197-200$.

27. Torzewski J, Li K, Zimmermann O (2011) Road Map to Drug Discovery and Development-Inhibiting C-reactive protein for the Treatment of Cardiovascular Disease. J Bioequiv Availab S1.

28. Kivity S, Ben-Haim M, Guranda L, Olchovsky D (2011) Shocking Liver Rheumatology 1:103.

29. Nellithady GS, Anila K, Kumar KK, Kaveri H (2010) Lack of Association of Chronic Liver Disease in Patients with Oral Lichen Lanus. J Carcinogene Mutagene 1:113

30. Hassan GM, Mazher KHM (2011) Genotoxicity and Histopathological Studies on the Liver, Kidney and Lymphocytes of Male Rats Fed on Diet Containing Waste Fat Released from Chicken During Grilling Process. J Cytol Histol 2:111.

31. Vinken M (2011) Mathieu Vinken's Work on the Role of Connexin-related Signalling in Hepatic Homeostasis and its Relevance for Liver-based In vitro Modelling. Pharm Anal Acta 2:101e.

32. Ferreira AK, Meneguelo R, Neto SC, Chierice GO, Maria DA (2011) Synthetic Phosphoethanolamine Induces Apoptosis Through Caspase-3 Pathway by Decreasing Expression of Bax/Bad Protein and Changes Cell Cycle in Melanoma. J Cancer Sci Ther 3: 053-059.

33. Karatepe O, Kurtulus I, Unal O, Yalcin O, Kemik A, et al. (2010) The Effect of Erythropoietin on Ischemic Colitis: An Experimental Rodent Model: Original Article . J Cytol Histol 1:108.

34. Kiuchi T, Tanaka K, Ito T, Oike F, Ogura Y, et al. (2003) Small-for-size graft in living donor liver transplantation: how far should we go? Liver Transpl 9: S29-S35.

35. Encke J, Uhl W, Stremmel W, Sauer P (2004) Immunosuppression and Modulation in Liver Transplantation. Nephrol Dial Transplant 19: 22-25.

36. O'Grady JG, Burroughs A, Hardy P, Elbourne D, Truesdale A (2002) Tacrolimus versus microemulsified ciclosporin in liver transplantation: the TMC randomised controlled trial. Lancet 360: 1119-1125.

37. Calne RY (1994) Immunosuppression in Liver Transplantation. N Engl J Med 331:1154-1155.

38. Mukherjee S, Mukherjee U (2009) A Comprehensive Review of Immunosuppression Used for Liver Transplantation. J Transplant 2009: 701464.

39. Vitin AA, Martay K, Vater Y, Dembo G, Maziarz M (2010) Effects of Vasoactive Agents on Blood Loss and Transfusion Requirements During Pre- Reperfusion Stages of the Orthotopic Liver Transplantation. J Anesthe Clinic Res 1:104.

40. Harring TR, Nguyen NT, Goss JA, O'Mahony CA (2011) Human T-Cell 
Citation: Hima Bindu A (2011) A New Era of Liver Transplantation - Radioembolization, a Novel Therapy for Hepatocellular Carcinoma. J Cancer Sci Ther S17. doi:10.4172/1948-5956.S17-012

Lymphoma Virus-Positive Allograft Used For Effective Orthotopic Liver Transplantation: A Case Report and Review of the Literature. J Transplant Technol Res 1:102

41. Lins Kusterer LEF (2011) Oral Diseases and Liver Pre and Post- Transplantation Disorders. J Transplant Technol Res S1:001.

42. Phuong-Thu TP, Phuong-Chi TP (2011) Predictive Diagnostic Tools for the Development of New Onset Diabetes Mellitus after Transplantation: An Overview. J Transplant Technol Res 1:103e.

43. Jasmine G, Yogeshwer S (2008) Prognostic Factors of Male Breast Cancer: Proteomic Approaches for Early Detection and Treatment. J Proteomics Bioinform 1: 112-127

44. Daniel BS, Murrell DF (2010) Chronic Urticaria Resolving after Resection of Mucinous Breast Cancer. J Clin Exp Dermatol Res 1:103.

45. EL-Shenawy NS, El-Ahmary B, Al-Eisa RA (2011) Mitigating Effect of Ginger against Oxidative Stress Induced by Atrazine Herbicides in Mice Liver and Kidney. J Biofertil Biopestici 2:107.

46. Umeshita K, Fujiwara K, Kiyosawa K, Makuuchi M, Satomi S, et al. (2003) Operative morbidity of living liver donors in Japan. Lancet 362: 687-690.

47. Son SK, Oh SH, Kim KM, Lee YJ, Jhang WK, et al. (2011) Successful liver transplantation following veno-arterial extracorporeal membrane oxygenation in a child with fulminant Wilson disease and severe pulmonary hemorrhage: A case report. Pediatr Transplant.

48. Zhao Y, Haney MJ, Mahajan V, Reiner BC, Dunaevsky A, et al. (2011) Active Targeted Macrophage-mediated Delivery of Catalase to Affected Brain Regions in Models of Parkinson's Disease. J Nanomedic Nanotechnol S4:003.

49. Nguyen KT (2011) Targeted Nanoparticles for Cancer Therapy: Promises and Challenges. J Nanomedic Nanotechnol 2:103e.

50. Rosen JE, Yoffe S, Meerasa A, Verma M, Gu FX (2011) Nanotechnology and Diagnostic Imaging: New Advances in Contrast Agent Technology. J Nanomedic Nanotechnol 2:115.

51. Douroumis D (2011) Mesoporous silica Nanoparticles as Drug Delivery System. J Nanomedic Nanotechnol 2:102e.

52. Meregalli M, Farini A, Torrente $Y$ (2011) Mesenchymal Stem Cells as Muscle Reservoir. J Stem Cell Res Ther 1:105.

53. Rameshwar P (2011) Post-identification of Cancer Stem Cell: Ethical and Scientific Dilemmas in Therapeutic Development? J Stem Cell Res Ther 1:e101.

54. Liu CY, Chang LC, Yang SW (2011) Metastatic Hepatocellular Carcinoma to the Nasal Cavity: A Case Report and Review of the Literature. J Cancer Sci Ther 3: 081-083.

55. Harring TR, Kuten DA, Nguyen NT, Goss JA, O'Mahony CA (2011) Orthotopic Liver Transplantation in Patients with Mixed Hepatocellular CarcinomaCholangiocarcinoma. J Transplant Technol Res 1:104.

56. Ibrahim SM, Lewandowski RJ, Sato KT, Gates VL, Kulik L, et al. (2008) Radioembolization for the treatment of unresectable hepatocellular carcinoma: A clinical review. World J Gastroenterol 14: 1664-1669.

57. Sangro B, Bilbao JI, Inarrairaegui M, Rodriguez M, Garrastachu P, et al. (2009) Treatment of hepatocellular carcinoma by radioembolization using $90 \mathrm{Y}$ microspheres. Dig Dis. 27: 164-169.

58. Llovet JM, Sala M (2005) Non-surgical therapies of hepatocellular carcinoma Eur J Gastroenterol Hepatol 17: 505-513.

59. Danobeitia JS (2011) Organ Transplantation in the Open-access Era. J Transplant Technol Res 1:102e.

60. Andrews JC, Walker SC, Ackermann RJ, Cotton LA, Ensminger WD et al. (1994) Hepatic radioembolization with yttrium- 90 containing glass microspheres: preliminary results and clinical follow-up. J Nucl Med 35: 1637-1644.

61. Luna LE, Kwo PY, Roberts LR, Mettler TA, Gansen DN et al. (2009) Liver transplantation after radioembolization in a patient with unresectable HCC. Nat Rev Gastroenterol Hepatol 6: 679-683.
62. Sai YRKM, Dattatreya A, Anand SY, Mahalakshmi D (2011) Biomarkers and their Role in Premonition, Interpretation and Treatment of Cancer. J Cancer Sci Ther R1:002.

63. Burrill J, Hafeli U, Liu DM (2011) Advances in Radioembolization- Embolics and Isotopes. J Nucl Med Radiat Ther 2:107

64. Kennedy A, Dezarn W, Weiss A (2011) Patient Specific 3D Image-Based Radiation Dose Estimates for 90Y Microsphere Hepatic Radioembolization in Metastatic Tumors. J Nucl Med Radiat Ther 2:111

65. Liu DM, Cade D, Klass D, Loh C, McWilliams JP, et al. (2011) Interventiona Oncology - Avoiding Common Pitfalls to Reduce Toxicity in Hepatic Radioembolization. J Nucl Med Radiat Ther 2:106.

66. Ettorre GM, Vennarecci G, Santoro R, Miglioresi L, Lepiane P, et al. (2011) Experiences in Hepatic Surgery and Transplantation after Radioembolization. $\mathrm{J}$ Nucl Med Radiat Ther 2:109.

67. Kennedy A, Nag S, Salem R, Murthy R, McEwan AJ, et al. (2007) Recommendations for radioembolization of hepatic malignancies using yttrium-90 microsphere brachytherapy: a consensus panel report from the radioembolization brachytherapy oncology consortium. Int J Radiat Oncol Biol Phys 68: 13-23.

68. Hill EJ, Sharma RA (2011) Multi-modality Therapy of Hepatic Metastases from Colorectal Carcinoma: Optimal Combination of Systemic Chemotherapy with Radio-embolization. J Nucl Med Radiat Ther 2:108.

69. Naga Deepthi CH, VVL Pavan Kumar A, Rameshbabu, Indirapriyadarshin U (2011) Role of Tumor Suppressor Protein p53 in Apoptosis and Cancer Therapy. J Cancer Sci Ther R1:001.

70. Gayed IW, Wahba H, Wan D, Joseph U, Murthy R (2010) Effect of Y-90 SIRSpheres Therapy for Multiple Liver Metastases in a Variety of Tumors. J Cancer Sci Ther 2: 043-046.

71. Sangro B, Iñarrairaegui M (2011) Radioembolization for Hepatocellular Carcinoma: Evidence-Based Answers to Frequently Asked Questions. J Nucl Med Radiat Ther 2:110.

72. Vouche M, Vanderlinden B, Delatte P, Lemort M, Hendlisz A, et al. (2011) New Imaging Techniques for $90 \mathrm{Y}$ Microsphere Radioembolization. J Nucl Med Radiat Ther 2:113.

73. Basciano CA, Kleinstreuer C, Kennedy AS (2011) Computational Fluid Dynamics Modeling of $90 \mathrm{Y}$ Microspheres in Human Hepatic Tumors. J Nuc Med Radiat Ther 2:112. 